\title{
Relationship between the type of delivery and the epidemiological profile of prenatal and perinatal assistance in a municipality of Minas Gerais
}

\section{Elvis Vieira da Silva 1}

https://orcid.org/0000-0002-7581-9075

Mariana Amorim de Andrade Costa 2

iD https://orcid.org/0000-0001-9575-7687

Karine Cristine de Almeida 3

https://orcid.org/0000-0002-1758-3957

Laís Moreira Borges Araujo 4

https://orcid.org/0000-0001-6748-0772

Natália de Fátima Gonçalves Amâncio 5

https://orcid.org/0000-0003-4006-8619

1,2,4,5 Centro Universitário de Patos de Minas. Rua Major Gote, 808. Caiçaras. Patos de Minas, MG, Brasil. CEP: 38.702-054. E-mail: elvisvieira@unipam.edu.br 3 Universidade Federal de Uberlândia. Uberlândia, MG, Brasil.

\begin{abstract}
Objectives: to describe the profile of prenatal and perinatal health by correlating it with sociodemographic and clinical conditions, verifying the effectiveness of health actions.

Methods: quantitative, descriptive and retrospective research using data from the Live Birth Information System (Sinasc) of the municipality of Patos de Minas in the period of 2011 to 2015 .

Results: between 2011 and 2014 there was a reduction in the rate of vaginal births and a slight increase in 2015, however, the rates of cesarean delivery were higher than recommended by the Ministry of Health. In both types of delivery, most pregnant women attended seven or more prenatal consultations, however, this rate was significantly higher for pregnant women who underwent cesarean section. Maternal age $>35$ years was also related to cesarean delivery, however, there was no significant relationship between type of delivery, the gestation time, birth weight and occurrence of maternal death.

Conclusions: during the analyzed period there were more cesarean sections in relation to vaginal deliveries, with no significant change in the number of maternal deaths. A significant association was found between the highest number of prenatal consultations and maternal age $>35$ years in pregnant women who underwent caesarean section. Verification of these associations can help in reorienting health practices in the region.
\end{abstract}

Key words Prenatal care, Perinatal care,Natural childbirth, Cesarean section 


\section{Introduction}

In recent decades, there has been a significant increase in cesarean rates in Brazil. Since 2009, the year in which the number of vaginal birth overcame, for the first time, the number of cesarean delivery, the rate of cesarean delivery continues to rise, accounting for $55.7 \%$ of births in 2012 . It is important to consider that this reality is not exclusive to Brazil, as it has been happening in some other countries, having as possible causes both the improvement of women's access to surgical procedures and the performance of cesarean by medical indication without technical criteria, that is, indiscriminately. In view of this scenario, it is essential to search for strategies to reduce these high rates, 1 which can occur since the beginning of the perinatal period.

According to the Ministry of Health, the perinatal period begins at 22 weeks, or 154 days of gestation and ends after seven full days of birth, that is, from 0 to 6 days of life, which is called the early neonatal period. ${ }^{2}$ In this context, prenatal care is of great importance to ensure that pregnant women are welcomed throughout the period of pregnancy, guaranteeing them, at the end of pregnancy, a better choice of the type of delivery and the birth of a healthy child. Likewise, postnatal care is extremely important, as it aims to ensure maternal and neonatal well-being after delivery. ${ }^{3}$

The provision of humanized and qualified services promotes adequate prenatal and postnatal care. This occurs through welcoming conducts and without unnecessary interventions, as well as easy access to health services, which must cover all levels of care: promotion, prevention and health care for pregnant women and newborns. It must also include inpatient and outpatient care. ${ }^{3}$

To assess the impact of social and economic changes, as well as the advances or setbacks in the availability and quality of health services, it is necessary to monitor the evolution of maternal and child health indicators.

According to Viellas et al., ${ }^{4}$ prenatal care in all regions of Brazil was higher than $90 \%$ independent of maternal condition. The study showed that, in Brazil, $75.8 \%$ of women start prenatal care before the $16^{\text {th }}$ week of pregnancy and $73.1 \%$ attended the minimum of six medical appointment recommended by the Ministry of Health. According to this study, the number of women that started early prenatal care and also attended enough medical appointment was lower in residents of the North and Northeast regions, and around women with low levels of education, women without a partner, with a higher number of previous gestations and around those who tried to terminate an unwanted pregnancy.

Due to the importance of perinatal care, this study is justified, since it is recommended by the Ministry of Health and has public policies with specific actions directed to prenatal, childbirth and postpartum. Thus, the objective of this study aims to outline the profile of prenatal and perinatal health in a municipality in Minas Gerais between 2011 and 2015 , relating them to some sociodemographic and clinical conditions, verifying the effectiveness of these actions.

\section{Methods}

This is a quantitative, descriptive and retrospective survey conducted in 2018, whose data were collected from the Live Birth Information System (Sinasc), 5 made available by the Informatics Department of the Unified Health System (Datasus), 6 at the electronic address (http://www.datasus.gov.br) corresponding to the municipality of Patos de Minas from January 2011 to December 2015.

According to the Brazilian Institute of Geography and Statistics (IBGE), the municipality of Patos de Minas is located in the mesoregion of Triângulo Mineiro and Alto Paranaíba, in the state of Minas Gerais, with an estimated population in 2018 of 150,833 inhabitants. 7

The study population consisted of pregnant women and newborns. The variables type of delivery, maternal age group, number of prenatal consultations, duration of pregnancy, maternal death and low birth weight were studied.

The sample was stratified by the number of births that occurred in the State of Minas Gerais, with a total of $1,314,477$ births, in the period from 2011 to 2015 . Of this total, only births that occurred in mothers living in the municipality of Patos de Minas in the same period, that is, 8,789 births if disregarding 3 births whose type was ignored. 5

As it is a public domain bank, it was not necessary to submit the project to the Research Ethics Committee (CEP).

The statistical analysis consisted of using the GraphPadPrism 7.0 program (GraphPad Software, Inc., San Diego, California, USA) for calculations of frequency, mean, standard deviation, correlations, relative risk, odds ratio and confidence interval. Data were presented in tables.

For media comparisons of maternal deaths and birth frequency (normal and cesarean operations), performed in Patos de Minas from 2011 to 2015, 
Shapiro-Wilk normality tests were performed to calculate the p-value. As the data displayed normal distribution or Gaussian distribution, thet test of Student (unpaired) was used. Values of $p<0.05$ were statistically assessed.

As correlations between the variables prenatal consultation, duration of pregnancy, birth weight and age at birth were analyzed regarding the type of delivery. The correlation was used using the chisquare tests $(p<0.05$ considered statistically significant). An analysis of these variables also consisted of calculating the relative risk (RR) using the Koopman asymptotic score and calculating the odds ratio using the Baptista-Pike method, as well as the confidence interval (95\%).

\section{Results}

In the period between the years 2011 and 2015, 8,789 births were registered in Sinasc, of which $3,403(38.7 \%)$ were vaginal deliveries, while 5,386 $(61.3 \%)$ were cesarean deliveries.

When analyzing Table 1, there was a reduction in the rate of vaginal delivery in the period from $2011(41.8 \%)$ to $2014(34.7 \%)$ with a decrease of $7.1 \%$ in that interval, and comparing the years between $2014(34.7 \%)$ and 2015 (36.7\%), an increase of $1.95 \%$ is observed. The rate of cesarean section operation showed a gradual increase in the period from 2011 to 2014, decreasing in 2015, reaching a variation of $3.1 \%$ comparing 2011 $(58.2 \%)$ and $2015(63.3 \%)$. The average vaginal deliveries between 2011 and 2015, of 680.6 ( \pm $26.02)$, is significantly lower $(p<0.001)$ than the average of cesarean delivery, of 1077 ( \pm 117.1), performed in the same period.

Among the variables analyzed, those that showed a significant association with the event under study, that is, the type of delivery, were: number of prenatal care visits (less than 6 or more than 6 visits) and maternal age (less than 35 or over 35 years), according to Table 2 .

Considering only vaginal delivery, 1,115 $(32.7 \%)$ women had up to six prenatal visits, while $2,282(67.0 \%)$ pregnant women attended seven or more care visits during pregnancy, six pregnant women $(0.18 \%)$ had their number of care visits ignored. As for cesarean delivery, of the total of 5,386 women, $1,053(19.5 \%)$ had up to six visits, while $4,325(80.3 \%)$ had seven or more $(\mathrm{RR}=1.489$; CI95\% $=1.412-1.569 ; p<0.001)$ (Table 2). The number of visits by eight $(0.15 \%)$ women who underwent cesarean section was ignored.

It can be analyzed in Table 2 that of the 3,403 vaginal deliveries, in $435(12.78 \%)$ pregnancies lasted less than or equal to 36 weeks, 2,940 ( $86.39 \%)$ lasted more than 36 weeks and only $28(0.82 \%)$ pregnancies this data was ignored. Regarding cesarean section, the data were similar: 708 (13.15\%) before 37 weeks, $4,653(86.3 \%)$ more than 36 weeks of gestation and $25(0.46 \%)$ ignored. It is noted that of the 1,143 premature births, the majority $(61.9 \%)$ occurred by cesarean section, however, there was no relationship between the type of delivery and the duration of pregnancy $(\mathrm{RR}=0.983$; CI95\% $=0.907-1.062 ; p=0.668$ ).

Most children who were born vaginally weighed more than $2500 \mathrm{~g}$, with $\mathrm{n}=3,060$ (89.9\%). Regarding cesarean delivery, most newborns were also born weighing more than $2500 \mathrm{~g}$, with $\mathrm{n}=4,806(89.2 \%)$. According to the World Health Organization (WHO), low birth weight appears to weigh less than $2500 \mathrm{~g}$, which was observed in $343(10.0 \%)$ vaginal births and $580(10.7 \%)$ cesarean delivery $(\mathrm{RR}=$ $0.955 ;$ CI95\% $=0.873-0.929 ; p=0.3045$ ) (Table 2). In three births the type of delivery was ignored, and these, two gestations lasted from 37 to 41 weeks, and in one pregnancy there was no disclosure of this data.

Regarding vaginal delivery, 3,093 (90.8\%) mothers gave birth under age of 35 years, with only 310 (9.1\%) being above the age mentioned. Performing the same analysis on cesarean operations, it can be seen that $4,354(80.8 \%)$ of mothers were under 35 years old, while 1,032 (19.1\%) underwent cesarean section over 35 years old $(\mathrm{RR}=$ $1,798 ;$ CI95\% $=1,627-1,992 ; p<0,001)$, verifying that for these women, cesarean section was more prevalent in the analyzed period (Table 2).

The number of deaths by type of delivery in Patos de Minas, in the period from 2011 to 2015, was on average eight $( \pm 2.915)$ for vaginal deliveries, with a confidence interval of 4.38-11.62, and $9.6( \pm 3,782)$ for cesarean operations, with a confidence interval of 4.905-14.3.

To check if there is a significant difference between the number of deaths by type of delivery in the period from 2011 to 2015 in the municipality of Patos de Minas, the Student's t test was applied, which showed a $p$-value of 0.4751 , not being a statistically significant difference. Thus, the two types of births pose similar risks for the occurrence of maternal mortality. 
Table 1

\begin{tabular}{lccccc}
\hline \multicolumn{2}{l}{ Frequency distribution of types of births performed in the municipality of Patos de Minas / MG, 2011-2015. } \\
\hline \multirow{2}{*}{ Year } & \multicolumn{2}{c}{ Vaginal delivery } & \multicolumn{2}{c}{ Cesarean section } & \multirow{2}{*}{ Total } \\
\cline { 2 - 5 } & $\mathrm{n}$ & $\%$ & $\mathrm{n}$ & $\%$ & \\
\hline 2011 & 701 & 41.8 & 975 & 58.2 & 1,676 \\
2012 & 695 & 41.4 & 982 & 58.5 & 1,677 \\
2013 & 669 & 39.5 & 1,021 & 60.4 & 1,690 \\
2014 & 640 & 34.7 & 1,203 & 65.3 & 1,843 \\
2015 & 698 & 36.7 & 1,205 & 63.3 & 1,903 \\
Total & 3,403 & 38.7 & 5,386 & 61.3 & 8,789
\end{tabular}

Source: Sinasc, 2011-2015.

Table 2

Analysis of births according to factors associated with the type of delivery in the municipality of Patos de Minas, MG (2011-2015).

\begin{tabular}{|c|c|c|c|c|c|c|c|c|}
\hline Variables & Total & $\begin{array}{l}\text { Vaginal } \\
\text { delivery }\end{array}$ & $\begin{array}{c}\text { Cesarean } \\
\text { delivery }\end{array}$ & $\chi^{2}$ & $\mathbf{R} \mathbf{R}$ & Odds ratio & $\mathrm{Cl} 95 \%$ & $p$ \\
\hline Prenatal visit & & & & 196.3 & 1.489 & 2.007 & $1.412-1.569$ & $<0.001$ \\
\hline Up to 6 & 2,168 & 1,115 & 1,053 & & & & & \\
\hline More than 6 & 6,607 & 2,282 & 4,325 & & & & & \\
\hline Pregnancy duration (weeks) & & & & 0.184 & 0.983 & 0.972 & $0.907-1.062$ & 0.668 \\
\hline$<36$ & 1,143 & 435 & 708 & & & & & \\
\hline$>36$ & 7,593 & 2,940 & 4,653 & & & & & \\
\hline Birth weight (g) & & & & 1.054 & 0.955 & 0.929 & $0.873-1.042$ & 0.304 \\
\hline$<2500$ & 923 & 343 & 580 & & & & & \\
\hline$>2500$ & 7,866 & 3,060 & 4,806 & & & & & \\
\hline Mother's age (years) & & & & 162.8 & 1.798 & 2.365 & $1.627-1.992$ & $<0.001$ \\
\hline$<35$ & 7,447 & 3,093 & 4,354 & & & & & \\
\hline$>35$ & 1,342 & 310 & 1,032 & & & & & \\
\hline
\end{tabular}

$\chi^{2}=$ Chi-square test; $\mathrm{RR}=$ relative risk; $\mathrm{Cl} 95 \%=95 \%$ confidence interval. Source: Adapted from the Live Birth Information System (Sinasc), Department of Informatics of the Unified Health System (Datasus), period 2011 to 2015.

\section{Discussion}

The results found in this study showed that there was a decrease in the number of vaginal deliveries in the periods between 2011 and 2014 and an increase in 2015, when compared to the previous year. For cesarean sections, there was a gradual increase in this rate between 2011 and 2014 and a small reduction in 2015. According to data released by Sinasc, 5 in Minas Gerais the incidence of deliveries in 2015 was 268,305 , with 115,964 vaginal deliveries, 151,741 cesarean delivery and 600 ignored. According to $\mathrm{WHO}$, the ideal is a rate of caesarean sections between $10 \%$ to $15 \%$ for the total population, however in Brazil the rates exceed $70 \%$ when considering the private service. ${ }^{8}$

In order to analyze the contribution of obstetric populations, specific to changes in cesarean rates, a study published in 2015 compared the numbers of cesarean sections in health facilities in 21 countries. In this study, it was identified between two surveys carried out by WHO that cesarean rates increased over time in all nations, except Japan. Although this increase was not new, it was found that the highest rates were registered in the least developed countries. Among these countries, there was support for previous reports of high rates of cesarean sections in Latin American countries, including Brazil.9

The increase in the rate of cesarean sections can have negative consequences for maternal health, since the risk of death is ten times higher when this procedure is performed compared to vaginal delivery. In addition, other risks such as bleeding, postpartum infections, pulmonary embolism and anesthetic complications are associated. The performance of cesarean sections also entails risks for newborns, such as respiratory problems, physiological jaundice, iatrogenic prematurity, anoxia, 
neonatal mortality and also increases the risk of admission to the Intensive Care Unit. 10

A study published in 201511 systematically analyzed ecological studies in which they correlated the rate of cesarean sections and their maternal, neonatal and infant outcomes. Studies that did not take into account the need for adjustment in relation to socioeconomic factors, clinical and demographic characteristics of the population, identified a strong inverse relationship between cesarean rates and mortality outcomes, concluding that maternal, neonatal and infant mortality decreased, while the cesarean rate rose above the limit, between 9 and $16 \%$. However, studies that adjusted socioeconomic factors found a weak or nonexistent relationship between these variables. It is also worth mentioning that, regardless of adjustments, cesarean rates above the $9-16 \%$ threshold were not associated with decreases in mortality outcomes.

Thus, it is possible to infer that cesarean rates below the threshold, socioeconomic development may be driving the ecological association between cesarean rates and mortality. On the other hand, at rates above this threshold, there is no association between cesarean section and mortality outcomes regardless of the adjustment. 11

For Oliveira et al.,12 in relation to the factors that lead to vaginal delivery or cesarean delivery, there are differences when comparing the public sector with the private sector. The authors showed in their study that the rate of cesarean section was higher in the private sector $(93.8 \%)$ than in the Unified Health System (SUS) (55.5\%). In SUS, the preference for cesarean section was related to previous cesarean section $(\mathrm{OR}=8.9$; CI95\% $=4.6-16.9)$, desire for cesarean section at the beginning of pregnancy $(\mathrm{OR}=2.0$; CI95\% = 1.1-3.6), pre-pregnancy overweight / obesity $(\mathrm{OR}=1.8 ; \mathrm{CI} 95 \%=1.1-2.8)$ and family income per capita higher than one minimum salary $(\mathrm{OR}=2.1 ; \mathrm{CI} 95 \%=1.3-3.4)$. In the private system, the desire for cesarean section at the beginning of pregnancy $(\mathrm{OR}=25.3)$ and a previous cesarean section $(\mathrm{OR}=11.3)$ were strongly associated with its realization. 12

In a study by Sakae et al.13 it was found that the obstetrician's profile has an important decisive factor for the increase in the number of cesarean sections, as they realized that those obstetricians who had amore interventionist characteristic performed almost three times more cesarean sections in relation to medical colleagues who chose births with less intervention. Still in this study, the authors identified some clinical factors related to a higher risk of cesarean sections, among them are: non- cephalic presentation, non-spontaneous progression delivery, twinning, less than three centimeters dilation, gestational pathologies and/or that precede the childbirth, prematurity or post-term.

Another issue to be taken into account is the doctor's belief in the preference of women for cesarean delivery.However, this would be just a way to justify the procedures rate increase, since the real reason would be the low ability of professionals to assist vaginal delivery and the greater convenience and profitability for them. ${ }^{14}$

Regarding the number of prenatal visits, at least six visits took place in $32.7 \%$ of vaginal deliveries and $19.5 \%$ of cesarean sections. On the other rand, seven or more visits took place in $67.0 \%$ of vaginal deliveries and $80.3 \%$ of cesarean sections. The type of delivery and the number of consultations had a positive association $(p<0.001)$. Pádua et al.15 also observed a positive association between the highest number of prenatal visits and the highest cesarean sections percentage. Pregnant women that have predisposing conditions to cesarean delivery, such as hypertension, preeclampsia and gestational diabetes, have visits more often. Therefore, a health situation of these pregnant women can be the determining factor for a higher frequency of cesarean sections. 15

In a study conducted in a city from Ceará state, with data collected from 124 pregnant patients, of whom 87 (70.1\%) underwent vaginal delivery and 37 (29.8) underwent cesarean section, demonstrated that $83.0 \%$ of pregnant women went to more than seven visits, while about $15 \%$ of pregnant women had between four and six consultations and $1.49 \%$ had only two prenatal visits. 16 Carvalho et al. 17 found in their study that there is a chance 2.94 times higher for a child with low weight in mothers with less than six prenatal visits. In the study by Silva et al., 16 the researchers did not found a correlation between the type of delivery and the number of consultations, however, a high percentage of pregnant women who had more than seven prenatal visits demonstrates relevance, as it is a means of reduce maternal and neonatal morbidity and mortality. The Ministry of Health, in accordance with WHO, recommends that pregnant women should have at least six prenatal visits, in case of habitual risk. Visits should be monthly up to a $28^{\text {th }}$ week, biweekly between 28 and 36 weeks andonce-a-week visit until the delivery. 18

The poor application of prenatal care is related to higher rates of maternal and child morbidity and mortality. Thus, adequate assistance to pregnant women ensures prevention of adverse events for both mothers and babies, in addition to enabling the 
identification of risk factors early and enabling safe intervention when necessary. ${ }^{19}$

In the present study, regardless of the type of delivery, there was a higher proportion $(86.3 \%)$ of births with a gestational duration of more than 36 weeks. In contrast, Guimarães et al. ${ }^{20}$ observed in a cross-sectional study using data from Sinasc, referring to births occurred in 2014, that among the group of women undergoing cesarean section there was a higher frequency of premature births and in the group of women undergoing vaginal delivery there was a higher frequency of term pregnancies.

Regarding the types of births and birth weight, there was a higher proportion of newborns weighing more than $2500 \mathrm{~g}$ for both types of births, however, among newborns with birth weight below $2500 \mathrm{~g}$, cesarean delivery stood out (61.9\%). Moreira et al.21 highlighted the relevance between type of delivery and birth weight. In their studies, the odds ratio for low birth weight was 2.3 for cesarean sections.

Regarding the type of delivery and mother's age, it was observed that among pregnant women over the age of 35 , cesarean section was more frequent, representing $76.9 \%(\mathrm{n}=1032)$ against $23.1 \%(\mathrm{n}=$ 310) vaginal deliveries. For Meller et al.,22 the prevalence of cesarean section was higher among women aged between 36 and 49 years, corroborating the findings of this study. Still in relation to mother's age, Carvalho et al. 17 identified in their study that the majority of low weight and premature babies were born to mothers aged between 14 and 25 years. The highest percentage of cesarean sections as the woman's age increases must be conditioned to the health situation of these pregnant women. There is a higher frequency of complications, such as hypertension and other chronic diseases among older pregnant women, which leads to greater chances of having a cesarean section. 15

It is concluded that there was a reduction in the occurrence of vaginal births in the period from 2011 to 2014 , and the number of cesarean deliveries increased gradually considering the same period, with the increase in the rate of this type of delivery comparing the year 2013 and 2014 was significantly higher than the other variations, with an increase of $4.86 \%$. In 2015, the last year analyzed in this study, there was an increase in the rate of vaginal births and a decrease in the rate of cesarean operations, which should be seen as positive, even though the rates are far removed from what is recommended by WHO and by the Ministry of Health.

It was also possible to conclude that most pregnant women do attend more than six prenatal visits, as recommended by the Ministry of Health. It was observed that in women who had a cesarean delivery as outcome, the prenatal care was more appropriate compared to women who had a vaginal delivery, the former having a $13 \%$ higher rate of attendance in more than six visits. However, it is worth highlighting the importance of investigating why a significant percentage of pregnant women did not have prenatal care as recommended by the health agency.

For the variable maternal death, there was no statistically significant correlation with the type of delivery, showing that it did not have a significant influence on the mortality of pregnant women.

Thus, although there is a high rate of caesarean delivery, health actions in the municipality of Patos de Minas have provided progress that influenced the fall in caesarean rates and the increase in the number of vaginal deliveries in 2015. It also influenced the offer of prenatal visits in an adequate amountfor most of the pregnant women, the expected duration for newborns, for the majority of pregnancies and low maternal mortality associated with complications of childbirth.

The identification of the correlations analyzed in this study allows, within the municipality of Patos de Minas, to recognize the effectiveness of health actions andassist in reorientationof their practices, allowing reformulation of actions that will contribute significantly for further improvement, helping to reduce high cesarean rates and improving health access for pregnant women so these have access to an adequate prenatal perinatal care, in addition to ensure a humanized service in the Unified Health System.

As a limitation of this research, we highlight the absence of comparative parameters of the municipality under study, for some of the evaluated attributes. Periodic assessments of information systems should be integrated into the routine of health surveillance systems. Quality information and updated databases are essential for analyzing health status and making evidence-based decisions. In the present study, the evaluated attributes and the usefulness of the Live Birth Information System ratify the quality and the importance of the information generated by it, in support of public maternal and child health policies. 


\section{Author's contribution}

Silva EV and Costa MAA performed data collection and analysis, and writing of the article. Almeida $\mathrm{KC}$ and Amâncio NFG participated in the data analysis and writing of the article. Araujo LMB revised the article. All authors approved the final version of the article.

\section{References}

1. Mascarello KC, Horta BL, Silveira MF. Complicações maternas e cesárea sem indicação: revisão sistemática e meta-análise. Rev Saúde Pública. 2017; 51: 105

2. Brasil. Ministério da Saúde. Secretaria de Atenção à Saúde. Pré-natal e Puerpério: atenção qualificada e humanizada manual técnico. Brasília, DF; 2005. [acesso em 5 Set 2018] Disponível em: bvsms.saude.gov.br/bvs/publicacoes/ manual_pre_natal_puerperio_3ed.pdf.

3. Gurgel RQ, Nery AMD, Almeida MLD, Oliveira ERR Lima DDF, Bettiol H, Barbieri MA. Características da gestações, partos e recém-nascidos da região metropolitana de Aracaju, Sergipe, Brasil. Rev Bras Saúde Mater Infant. 2009; 9 (2): 167-77.

4. Viellas EF, Domingues RMSM, Dias MAB, Gama SGN, Filha MMT, Costa JV, Bastos MH, Leal MC. Assistência pré-natal no Brasil. Cad Saúde Pública. 2014; 30: 85-100.

5. Brasil. Ministério da Saúde. Departamento de Informática do SUS. Microdados do Sistema Informação sobre Nascidos Vivos. Brasília, DF; 2015.

6. Brasil. Ministério da Saúde. Banco de dados do Sistema Único de Saúde-DATASUS. [acesso em 3 Set 2018]. Disponível em: http://datasus.saude.gov.br.

7. Brasil. Instituto Brasileiro de Geografia e Estatística IBGE. [acesso em 5 Nov 2018]. Disponível em: https://cidades.ibge.gov.br/brasil/mg/patos-de-minas/ panorama.

8. Mandarino NR, Chein MBC, Júnior FCM, Brito LMO, Lamy ZC, Nina VJS, Mochel EG, Neto JAF. Aspectos relacionados à escolha do tipo de parto: um estudo comparativo entre uma maternidade pública e outra privada, em São Luís, Maranhão, Brasil. Cad Saúde Pública. 2009; 25 (7): 1587-96.

9. Vogel JP, Betrán AP, Vindevoghel N, Souza JP, Torloni MR, Zhang J, Tunçalp Õ, Mori R, Morisaki N, Ortiz-Panozo E, Hernandez B, Pérez-Cuevas R, Qureshi Z, Gülmezoglu AM, Temmerman M, WHO Multi-CountrySurveyon Maternal andNewborn Health Research Network. On behalf of the WHO Multi-Country Survey on Maternal and Newborn Health Research Network. Use of the Robson classification to assess caesarean section trends in 21 countries: a secondary analysis of two WHO multicountry surveys. Lancet Global Health. 2015; 3 (5): e260-70.

10. Anjos CS, Westphal F, Goldman RE. Cesárea Desnecessária no Brasil: Revisão integrativa. Enferm Obst. 2014; 1 (3): 86-94.

Received on December 17, 2018

Final version presented on October 31, 2019

Approved on December 27, 2019
11. Betran AP, Torloni MR, Zhang J, Ye J, Mikolajczyk R, Deneux-Tharaux C, Oladapo OT, Souza JP, Tunçalp Õ, Vogel JP, Gülme-zoglu AM. What is the optimal rate of caesarean section at population level? A systematic review of ecologic studies. Reprod Health. 2015; 12 (1): 57.

12. Oliveira RR, Melo EC, Novaes ESN, Ferracioli PLRV, Mathias TAF. Fatores associados ao parto cesárea nos sistemas público e privado de atenção à saúde. Rev Esc Enferm USP. 2016; 50 (5): 734-41.

13. Sakae Thiago Mamôru, Freitas Paulo Fontoura, d'Orsi Eleonora. Fatores associados a taxas de cesárea em hospital universitário. Rev Saúde Pública. 2009; 43 (3): 472-80.

14. Riscado LC, Jannotti CB, Barbosa RHS. A decisão pela via de parto no Brasil: temas e tendências na produção da saúde coletiva. Texto Contexto Enferm. 2016; 25 (1): e3570014.

15. Pádua KS, Osis MJD, Faúndes A, Barbosa AH, Moraes Filho OB. Fatores associados à realização de cesariana em hospitais brasileiros. Rev Saúde Pública. 2010; 44 (1): 709

16. Silva MCRG, Silva LSR, Sousa JO, Frota MCQA, Carneiro JKR, Oliveira MAS. Perfil epidemiológico-obstétrico e sociodemográfico de gestantes atendidas em um centro de saúde da família. Rev Saúde Desenvol. 2019; 13 (14): 10011

17. Carvalho SS, Coelho JMF, Soares DABS, Mariola E. Fatores maternos para o nascimento de recém-nascidos com baixo peso e prematuros: estudo caso-controle. Ciênc Saúde. 2016; 9 (2): 76-82.

18. Brasil. Ministério da Saúde. Secretaria de Atenção à Saúde. Atenção ao pré-natal de baixo risco. Brasília, DF; 2012. [acesso em 5 Set 2018]. Disponível em http://bvsms.saude.gov.br/bvs/publicacoes/cadernos_atenca o_basica_32_prenatal.pdf.

19. Nunes JT, Gomes KRO, Rodrigues MTP, Mascarenhas MDM. Qualidade da assistência pré-natal no Brasil: revisão de artigos publicados de 2005 a 2015. Cad Saúde Coletiva. 2016; 24 (2): 252-61.

20. Guimarães RM, Silva RLPD, Dutra VGP, Andrade PG, Pereira ACR, Jomar RT, Freire RP. Fatores associados ao tipo de parto em hospitais públicos e privados no Brasil. Rev Bras Saúde Mater Infant. 2017; 17 (3): 581-90.

21. Moreira AI, Sousa PR, Sarno F. Baixo peso ao nascer e seus fatores associados. Einstein. 2018; 16 (4): 1-6.

22. Meller FO, Schäfer AA. Fatores associados ao tipo de parto em mulheres brasileiras: PNDS 2006. Ciênc Saúde Coletiva. 2011; 16 (9): 3829-35. 